\title{
A Ferrovia como Elemento de Geração de Turismo e Patrimônio
}

\author{
D'AGOSTINI, Fernanda Figueiredo ${ }^{1}$ \\ ABASCAL, Eunice H. Sguizzardi² \\ ${ }^{1}$ Universidade Anhembi Morumbi, São Paulo, Brasil. E-mail: arq.fernandafd@gmail.com \\ ${ }^{2}$ Universidade Presbiteriana Mackenzie, São Paulo, Brasil. E-mail: eunicehab@gmail.com
}

\section{Resumo}

O patrimônio cultural tem revelado importância e visibilidade em propostas de desenvolvimento de produtos e roteiros turísticos. As regiões buscam maior diversificação de ofertas culturais, destacando-se a preocupação com o patrimônio ferroviário, que no Brasil, passou por um processo de privatização na década de 1990, decorrente do declínio da eficiência do sistema ferroviário, desencadeado nos anos de 1940. Este artigo tem o objetivo de analisar algumas das ferrovias brasileiras que sofreram algum tipo de implemento turístico, avaliando as políticas de âmbito urbano-regional adotadas e as possibilidades de desenvolvimento proporcionadas por meio de um plano nesses níveis, com ênfase na manutenção e preservação do patrimônio ferroviário, articuladas ao desenvolvimento de atividades turísticas. No entanto, ressalta-se que esta importância e visibilidade estão muito aquém do necessário para a preservação do patrimônio ferroviário, tornando a contextualização histórica e a fundamentação destes processos cruciais para melhor entendimento do processo de decadência e desvalorização das ferrovias no Brasil.

Palavras-Chave: Patrimônio $\quad$ Ferroviário;
Políticas Públicas; Ferrovias
Planejamento Regional.

\begin{abstract}
Cultural heritage has revealed importance and visibility in product development and tourist itineraries proposed. Regions seek greater diversification of cultural offerings, highlighting the concern over the railroad heritage, which in Brazil, underwent a privatization process in the 1990s, due to the decline of the rail system efficiency, initiated in the 1940s. This article aims to analyze some of the Brazilian railways that suffered some kind of tourist implement, evaluate the urban-regional policies adopted and development possibilities offered by a plan at these levels, with emphasis on the maintenance and preservation of the railway heritage, linked to the development of tourist activities. However, it is emphasized that this importance and visibility are far short of the need to preserve the railway heritage, making the historical context and the reasons these processes crucial for the better understanding of the decay process and devaluation of railways in Brazil.
\end{abstract}

Key-Words: Heritage Railway; Public Policy; Tourist Railways; Regional Planning. 


\section{Introdução}

Uma das principais características da sociedade contemporânea é a velocidade de suas transformações, o que suscitou a necessidade de novos meios e instrumentos para o desenvolvimento das cidades e das regiões. A valorização e a promoção de uma lógica cultural relacionada à promoção e oferta dos territórios, fundamentada no turismo, buscando fluxos de pessoas, bens e de capital no território são reflexo da inserção das cidades e regiões na economia global, acarretando o aumento dos atores envolvidos nas políticas públicas, contribuindo para uma maior complexidade.

No final do século XX o turismo tornou-se um elemento central na estratégia de desenvolvimento de muitas cidades, sendo particularmente atraente aos governos por oferecer uma alternativa a outras formas de desenvolvimento econômico, por sua capacidade de geração de empregos, divisas e promoção das regiões (GOLDFARD, 1989 apud WEARING e NEIL, 2001).

Para Montaner (2014) a complexidade dos processos socioculturais gerados pelo turismo é o fenômeno que melhor sintetiza as contradições da sociedade contemporânea, revelando tensões e a necessidade de escolhas, frente à diversidade de interesses e conflitos desencadeados: a cidade é o espaço em que se manifestam tensões tais como friç̧ões entre regional e local, bem como o enfrentamento de uma tendência à homogeneização de hábitos e produtos, contra a manutenção da memória viva e identidades.

Desta forma, esse autor (2014) considera o turismo como um sistema de atividades que se sobrepõe às estruturas existentes, podendo contribuir para o sucesso ou esgotar, empobrecer e destruir os sistemas naturais, sociais e urbanos. No entanto, a energia e riqueza geradas pela atividade turística podem ser utilizadas de forma a promover o desenvolvimento e enriquecer os tecidos sociais, produtivos, urbanos e paisagísticos que não têm meios próprios suficientes para consegui-lo.

Neste cenário, o patrimônio histórico passa a integrar uma oferta instrumental como um meio entre outros para fomentar a atividade turística, e um dos elementos a considerar para o planejamento urbano-regional, que para atender à demanda provinda das transformações urbanas recentes, deve ser gerido de forma a propiciar maior flexibilidade de decisão, além de urgir análises de cenários alternativos e a inclusão da sociedade para a formulação das políticas públicas afins.

A consideração da preservação do patrimônio histórico e cultural em planos e projetos urbanos e regionais torna-se uma maneira de promover sua articulação com a política de desenvolvimento do território, e assim viabilizar sua implementação e financiamento. A preservação do patrimônio depende de mecanismos de inclusão em planos diretores, leis de diretrizes orçamentárias, planos plurianuais etc., caracterizando um modo de articulação entre a conservação e o planejamento urbano (SOMEKH, 2014).

Aventa-se uma nova lógica de preservação, que vê no patrimônio um recurso imprescindível para o desenvolvimento urbano e regional, e para a articulação do crescimento econômico e turístico à conservação e valorização do patrimônio natural e cultural. O patrimônio ferroviário pode então ser associado a uma paisagem ferroviária, buscando novos significados e resguardando a memória e valores vinculados a história da ferrovia e do patrimônio que a cerca; destacando-se para o sucesso dessa política a importância da integração horizontal das diversas políticas públicas setoriais.

\section{Ferrovias e Desenvolvimento Urbano}

O patrimônio ferroviário e respectivos meios de transporte agregados, os trens por excelência, são recursos capazes de afirmar uma situação cultural e assim estimular o turismo em âmbito urbano e regional, como um meio para o desenvolvimento. A atividade turística tem impactos econômico-sociais nas diversas regiões em que é implementada, pois estimula a geração de emprego e renda (JENKINS e LICKORISH, 2000).

São diversas as consequências da implementação turística relativas ao impacto econômico na região afetada, no que diz respeito ao desenvolvimento local e regional.

Os impactos sobre um possível desenvolvimento de nível regional ocasionados pelo turismo são os principais argumentos que levam planejadores 
econômicos a optar por essa atividade.

Essa atividade turística de abrangência territorial (urbana e regional) apoiada no turismo pode se valer do aproveitamento de locais e bens de significativo valor histórico-cultural, pois pode potencializar o desenvolvimento de lugares e regiões que demonstram pouca diversidade de atividades econômicas.

A implantação de atividades do setor secundário, tais como pequenas indústrias ou manufaturas, revelamse hoje insuficientes para sustentar economicamente os municípios, o que os leva a uma necessidade de integrar-se em redes, pautadas nas possibilidades das regiões que os relacionam. Tal premência por uma outra escala de abrangência estimula os planejadores a se voltarem para o turismo de alcance regional. As atividades de prestação de serviços tais como o turismo ferroviário, devido a suas características de geração de mobilidade e penetração regional passam a estimular a atividade econômica em regiões desfavorecidas de outros setores da economia, e que dispõem de um patrimônio cultural e natural passível de ser explorado (JENKINS e LICKORISH, 2000, p. 102). O turismo atinge assim uma condição de atividade necessária e benéfica ao desenvolvimento das regiões, que se demonstram carentes de outros recursos de desenvolvimento.

O primeiro fator da existência da atividade turística é de natureza econômica, e diz respeito à disponibilidade de renda real, ou poder de consumo em situações inflacionárias (JENKINS e LICKORISH, 2000). Além do fator meramente econômico, renda real para arcar com os custos da viagem, há outros fatores relativos a atratividade, que desencadeiam a procura por parte dos turistas para realizar determinado roteiro, viagem ou visitar destinos.

Além da mobilidade e extensão de um roteiro ferroviário, e o fato de alcançarem um conjunto de cidades na região, outros fatores relacionados incluem oferta de hospedagem e acesso fácil ao destino. A oferta e a qualidade do serviço turístico, junto a disponibilidade de renda do consumidor, impactam o turismo local e regional. Para o sucesso de um roteiro ferroviário, voltando ao objeto que nos interessa, é preciso criar as melhores condições para que uma cultura turística de fruição do patrimônio ferroviário seja então criada (DIAS, 2006, p.28). Desenvolvimento de roteiros turísticos vinculados às ferrovias o patrimônio histórico, ambiental e cultural correlato são, na contemporaneidade, uma forma possível para fomentar atividades intermunicipais de alcance regional.

De um ponto de vista histórico, a implantação das redes ferroviárias na Europa e América foi de extrema importância para o desenvolvimento econômico, tanto para os países do hemisfério Norte, quanto para os países por eles colonizados, em virtude de representarem um meio indispensável para a crescente distribuição da produção crescente no mercado mundial, enquanto constituiu uma forma de continuidade dos veículos e do domínio tecnológico, comercial e financeiro. Neste cenário a Grã-Bretanha destacou-se como polo gerador de técnicas, de tecnologia e de produção industrial de material ferroviário, influenciando a conformação dos modelos de implantação de redes em todo o mundo, e também as técnicas de organização do território, bem como o modo de apropriação da tecnologia e sistemas de construção (CYRINO, 2004).

Nos países industrializados, como a Grã-Bretanha e outros na Europa Ocidental, a expansão ferroviária associou-se ao desenvolvimento da indústria e consolidação de uma política econômica liberal, contrariamente aos países cujo crescimento dependeu de exploração de matérias-primas e produção agrária, destinados às regiões industrializadas, das quais recebiam produtos manufaturados, bens ou investimentos de capital (CYRINO, 2004).

A ferrovia, como resultado da inovação tecnológica passou a ser novo elemento propulsor das relações internacionais, consolidando-se como produto da era industrial e instrumento para a dinamização do transporte de mercadorias e a ligação dos crescentes centros industriais europeus e norte-americanos em expansão (ALLIS, 2006).

Diferentemente dos países europeus onde as ferrovias foram utilizadas de forma estratégica para a articulação territorial e conexão dos centros urbanos, as primeiras linhas férreas do Brasil foram construídas para atender fundamentalmente a 
demanda de escoamento da produção agrícola até o porto mais próximo. A ferrovia tem papel fundamental no desenvolvimento do Brasil no período em que o café foi o principal condutor da economia brasileira.

Além da estrada de ferro Santos - Jundiaí, principal eixo de escoamento da produção do café paulista, outras ferrovias brasileiras ganham destaque por seu papel econômico e por seu conjunto tecnológico e arquitetônico como, por exemplo, a estrada de ferro entre Curitiba e Paranaguá construída na década de 1880, responsável pelo transporte de grande parte da erva mate produzida no Paraná e embarcada no porto de Paranaguá (ALLIS, 2005).

A expansão da malha ferroviária brasileira do final do século XIX e início do século XX, tem forte representação na região Sul pela Estrada de ferro São Paulo - Rio Grande, construída entre 1890 e 1910, porém é na região centro-oeste onde está a maior concentração desta expansão, constituída pelas vias férreas: Estrada de Ferro Central do Brasil, Ferrovia Central - Atlântica (FCA) e Estrada de Ferro Oeste de Minas - EFOM (ABPF, 2014).

As ferrovias, durante algumas décadas, foram responsáveis pela caracterização de regiões, pois promoveram transformações nas cidades existentes por onde passam e, em muitos casos, a fundação de novos municípios. Influíram na configuração de ruas e em seu sistema de identificação, nos meios de transportes urbanos e no estabelecimento de atividades complementares nos arredores das estações, como por exemplo, comércios e hotéis (KUHL, 1998).

No início do século XX a rápida evolução do transporte rodoviário culminou na década de 1940 com sua competição com o transporte ferroviário que tem por consequência o início do processo de decadência e desvalorização do sistema ferroviário no Brasil, mais tarde alimentada pelas consequências da deflagração da Segunda Guerra Mundial, que dificultou a importação do carvão e do material ferroviário, além do forte nacionalismo gerado no governo de Getúlio Vargas (MAZZOCO; SANTOS, 2005).

[...] no ano de 1908 (...) começou a funcionar (...) a primeira montadora de veículos automotores, enquanto a rede ferroviária nacional tinha extensão de 18.633 quilômetros, equivalentes a 50,33\% da extensão que esta mesma rede iria atingir em 1952. O ritmo do crescimento da rede ferroviária brasileira diminuiu a partir da década de 20, sendo que, entre 1930 e 1950, não foram realizadas substituição ou expansão material, a fim de repor material desgastado e atender às necessidades de modernização e ao aumento do tráfego, enquanto a extensão da rede crescia apenas 10,33\% entre 1930 e 1949 , tendo apresentado, no período de 1950 a 1962, um decréscimo de $0,3 \%$, consequência da eliminação de ramais economicamente não justificados (MAZZOCO; SANTOS, 2005, p.96).

Em 1957 o então Presidente da República Juscelino Kubitschek cria a Rede Ferroviária Federal S.A. (RFFSA), como uma sociedade de economia mista integrante da Administração Indireta do Governo Federal, vinculada funcionalmente ao Ministério dos Transportes. A RFFSA era a consolidação de 18 ferrovias regionais, com o objetivo principal de promover e gerir os interesses da União no setor de transportes ferroviários (RFFSA, 2014).

Em 1992, a RFFSA foi incluída no Programa Nacional de Desestatização, ensejando estudos, promovidos pelo Banco Nacional de Desenvolvimento Econômico e Social BNDES, que recomendaram a transferência para o setor privado dos serviços de transporte ferroviário de carga. Essa transferência foi efetivada no período 1996/1998, de acordo com o modelo que estabeleceu a segmentação do sistema ferroviário em seis malhas regionais, sua concessão pela União por 30 anos, mediante licitação, e o arrendamento, por igual prazo, dos ativos operacionais da RFFSA aos novos concessionários. Em 1998, houve a incorporação da Ferrovia Paulista S.A. - FEPASA à RFFSA, ao que se seguiu, em dezembro desse ano, a privatização daquela malha (RFFSA, 2014).

A liquidação da RFFSA foi iniciada em 17 de dezembro de 1999; este processo implicou na realização dos ativos não operacionais e no pagamento dos passivos. Os ativos operacionais (infraestrutura, locomotivas, vagões e outros bens vinculados à operação ferroviária) foram arrendados a concessionárias operadoras das ferrovias (RFFSA, 2014).

A política de privatização apresentada abriu uma 
lacuna na preservação e manutenção do patrimônio edificado das ferrovias, cuja preservação não veio sendo realizada, entre outras razões, devido a despender muitos recursos sem geração de contrapartidas. Desta forma, as concessionárias deixaram de atribuir devida atenção ao valor patrimonial histórico e cultural agregado à ferrovia. As condições de contribuição das ferrovias ao desenvolvimento, quer regional ou nacional, transformaram-se, na transição de uma sociedade industrial para outra, de serviços.

$\mathrm{Na}$ atualidade, a atividade turística se propõe a integrar a ferrovia e seu patrimônio à economia, em escala regional. As formas como os denominados roteiros turísticos ferroviários são abordados, de forma a funcionarem como instrumentos de articulação de atividades econômicas regionais são o objeto de análise crítica a seguir realizada, a partir de alguns casos selecionados: a ferrovia Curitiba Paranaguá, no Paraná, alguns trechos da ferrovia Santos - Jundiaí, além das ferrovias turísticas implementadas no estado de Minas Gerais que integram o complexo das cidades históricas.

\section{Ferrovia, Patrimônio e Turismo}

$\mathrm{Na}$ tentativa de preservação do legado das companhias ferroviárias, do patrimônio da história da arquitetura, da engenharia e da técnica, algumas ferrovias brasileiras foram transformadas em "ferrovias turísticas". Trataremos de apresentar alguns casos, e ponderar sobre os efeitos da implementação de roteiros turísticos ferroviários e o alcance desta ação para o desenvolvimento regional.

Abordaremos os casos da ferrovia Curitiba Paranaguá, no Paraná, e de alguns trechos da própria ferrovia Santos - Jundiaí, além das ferrovias turísticas implementadas no estado de Minas Gerais que integra o complexo das cidades históricas.

Em todos esses exemplos a implantação de um roteiro turístico agregado a um plano de desenvolvimento regional tornou-se fundamental para a manutenção e preservação do patrimônio

1 O Barreado é um prato típico do litoral paranaense, de influência portuguesa tem base de carne bovina (de segunda qualidade - patinho, maminha, paleta e etc.) temperada com toucinho, cominho e louro. Esses ingredientes são cozidos em panela de barro selada com uma mistura de farinha de mandioca, ferroviário, e também da sustentabilidade das regiões onde estão instaladas.

\subsection{A Estrada de Ferro Curitiba- Paranaguá}

No Paraná, no trecho entre a capital Curitiba e a cidade litorânea de Morretes, ao longo da estrada de ferro Curitiba - Paranaguá, opera o trem turístico que se distingue por sua regularidade diária. $\mathrm{O}$ turismo implementado nesta região, formada pelos municípios de Curitiba, Morretes e Antonina, baseia-se principalmente no valor cultural o patrimônio imaterial da cidade de Morretes, apropriando-se de sua culinária diferenciada, com destaque ao prato típico chamado "Barreado"1. Além desse atrativo, a cidade oferece ao visitante uma diversificada configuração urbanística e arquitetônica que remonta ao século XVI.

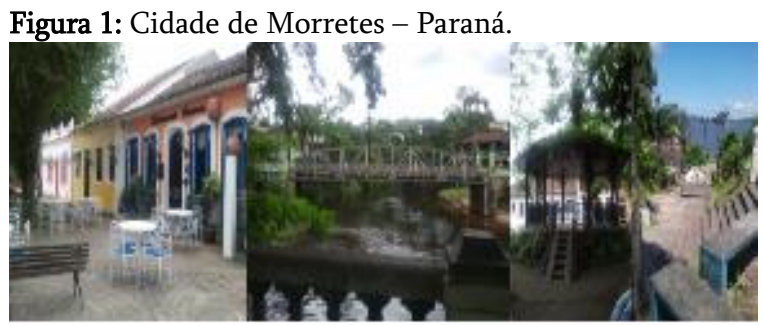

Fotos: Fernanda F. D’Agostini, 2012

Com duração de três horas, a viagem entre Curitiba e Morretes proporciona aos turistas a contemplação das paisagens naturais da mata atlântica, além da observação do patrimônio edificado ao longo da ferrovia pertencentes a ferrovia - inclusive na época de sua construção, que guarda um valor histórico e cultural de uma época ${ }^{2}$. Porém boa parte deste patrimônio encontra-se deteriorado ou mesmo em estado de ruína, como apresentado na Figura 2; somente os edifícios em que a ALL (atual RUMOALL, a partir da fusão das duas empresas em 2015) faz uso apresentam sutil diferença em seu estado de conservação.

As dificuldades de gestão advindas da privatização das ferrovias se manifestam na conservação do patrimônio, que deveria ser uma das principais propulsoras da atividade turística. A pretendida

cinza de fogão e água e, em alguns casos, também com uma folha de bananeira, desta técnica de "barrear" originou-se o nome do prato (GIMENES, 2009)

2 Observações realizadas pela autora em viagem realizada em janeiro de 2012. 
revitalização da região e dos municípios relacionados pelo roteiro turístico ferroviário não pode lograr dessa maneira seu máximo êxito:

A preservação do patrimônio neste trecho, cerca de 110 quilômetros, ainda é uma questão em aberto, muito em função das pendências decorrentes da privatização das ferrovias. A Rede Federal Ferroviária S/A, antiga empresa estatal responsável pelo transporte ferroviário no Brasil e atualmente em liquidação, ainda é responsável por boa parte do patrimônio construído desta ferrovia - bem como de outras pelo território nacional. No entanto, dadas as condições financeiras e jurídicas, a estatal tem feito gestões no sentido de delegar significativa parcela do patrimônio de valor histórico remanescente a partes que se proponham as atividades em favor de sua preservação. Isso decorre, principalmente, do fato de as concessões contratuais realizadas em meados da década de 1990 terem repassado à iniciativa privada apenas parte deste acervo, eminentemente vinculado à operação comercial de cargas do Porto de Paranaguá (ALLIS, 2005, p.156).

Figura 2: Patrimônio edificado da Ferrovia Curitiba Morretes

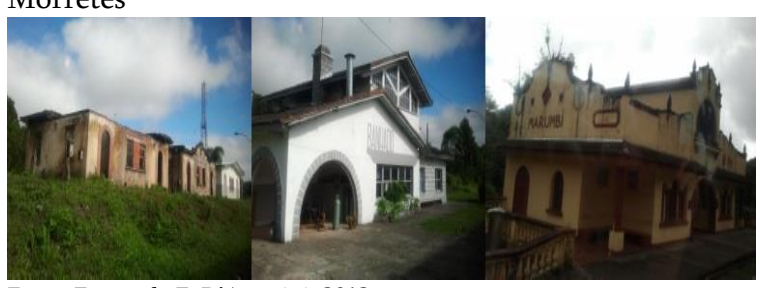

Fotos: Fernanda F. D'Agostini, 2012

O processo de fortalecimento da memória e resgate do patrimônio ferroviário na região alvo de análise já fora intensificado na cidade de Curitiba com a instalação do Museu Ferroviário, um dos pontos turísticos que fazem parte do roteiro realizado pelo ônibus circular criado para atendimento exclusivo aos turistas naquela cidade. $\mathrm{O}$ patrimônio edificado foi restaurado e sofreu algumas modificações para a implantação de um shopping center anexo ao museu que recebe o nome de Estação, como meio de preservação da memória e integração da população à ferrovia por meio de acesso ao pátio do shopping, antiga gare, em que remanescem alguns vagões que desempenham papel referencial, como ponto de encontro e de instalação de um café.

Salienta-se que este museu e shopping center não possuem nenhum tipo de integração com o passeio de trem Curitiba-Morretes, assim como este não faz parte do roteiro turístico principal da cidade, que possui como condutor o ônibus, dificultando sua divulgação e conhecimento da ferrovia turística pelos visitantes, contrariando as prerrogativas do desenvolvimento regional por meio do turismo, fragilizando a proposta de uma real integração econômica utilizando o roteiro turístico, e revelando uma desarticulação de atividades e do território.

\subsection{O Trem Turístico em Minas Gerais: roteiro das cidades históricas}

O estado de Minas Gerais é o que mais tem se beneficiado da implementação do turismo cultural por meio das ferrovias, instalado ao longo das vias férreas que compõem a antiga FCA - Ferrovia Centro - Atlântica. O trem turístico integra o complexo das cidades históricas, fortalecendo a mobilidade urbana entre as cidades e a própria gestão do turismo aplicado ao desenvolvimento local.

Como no caso do estado do Paraná, observa-se em Minas Gerais um esforço de regionalização em prol do desenvolvimento e sustentabilidade de municípios que compõem um roteiro turístico, assim como o trem como um produto turístico enfatizando a promoção da atividade na região.

A Vale - concessionária da malha operada anteriormente pela FCA, que teve origem na RFFSA, a qual já fora incluída no Plano Nacional de Desenvolvimento - PND por meio do Decreto no. 473/92, neste momento implementou novos padrões de administração e gestão do patrimônio ligados ao transporte ferroviário de cargas. Seguindo as diretrizes então referenciadas por um planejamento histórico, a empresa concessionária mantém um trem turístico com saídas nos finais de semana e feriados, partindo de Ouro Preto e chegando à Mariana, duas importantes cidades do Sul de Minas e representantes do patrimônio cultural e natural (VALE, 2014).

A construção do ramal de Ouro Preto foi iniciada em 1883 , tendo seu prolongamento até Mariana concluído em 1914. Ao longo deste percurso, com cerca de $18 \mathrm{~km}$, todo o complexo arquitetônico do qual a ferrovia faz parte passou por um processo de revitalização em 2006 (Figura 3), patrocinado pela Vale em cumprimento às exigências contratuais de concessão (FCA, 2014). 
Figura 3: Patrimônio ferroviário de Ouro Preto requalificado

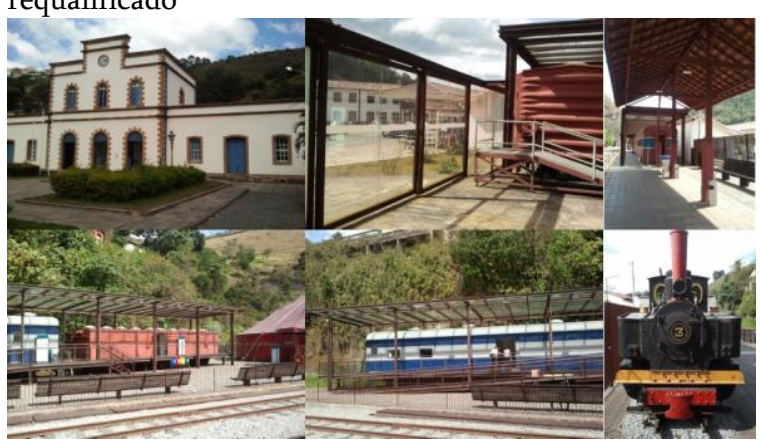

Fotos: Fernanda F. D'Agostini, 2012

Compondo o roteiro das cidades históricas, a Estrada de Ferro Oeste de Minas - EFOM, inaugurada no dia 30 de setembro de 1881, ligava a princípio, as cidades de Antônio Carlos e Barroso, e em 1996 passou a fazer parte da FCA. No trecho entre as cidades de São João Del Rei e Tiradentes foi implantado o trem turístico; o percurso possui $12 \mathrm{~km}$ e na Estação de São João Del Rei encontra-se o Museu Ferroviário. Nele o turista tem a oportunidade de apreciar documentos, equipamentos e veículos ferroviários que fazem parte da história desta ferrovia, além de locomotivas de vários períodos (FCA, 2014).

Neste trecho, assim como em outros diversos casos da malha ferroviária brasileira, observa-se que não há uma preocupação relevante com a manutenção e preservação do patrimônio edificado; a estação ferroviária de Tiradentes não apresenta nenhum tipo de benfeitorias para apoio e conforto do turista, assim como a edificação se mantém em estado de conservação precário conforme demonstrado na imagem a seguir.

Figura 4: Estação de Tiradentes/ MG

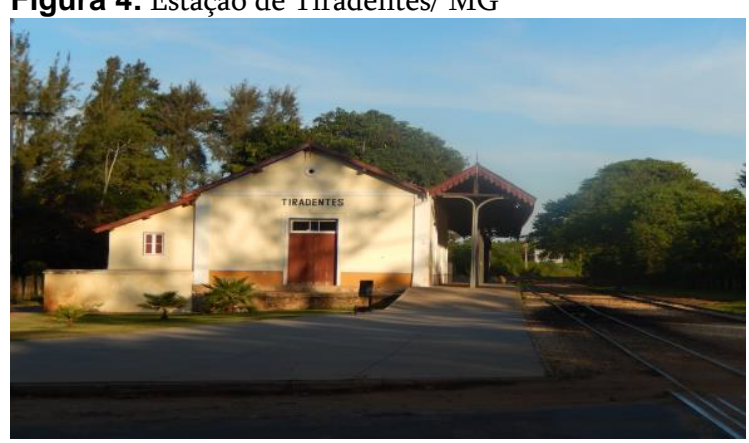

Fotos: Fernanda F. D'Agostini, 2012

3 Dado levantado pela autora, Fernanda F. D'Agostini, em viagem realizada em janeiro de 2015.
A associação de um museu à ferrovia e ao passeio demonstra a preocupação do programa em alcançar uma abrangência regional fundamentada na valorização da memória e da imagem das cidades envolvidas, assim como na preservação e educação patrimonial.

A Vale ainda administra um dos maiores percursos de um trem de passageiros realizado no território brasileiro, interligando as capitais Belo Horizonte Minas Gerais à Vitória - Espírito Santo.

Esta linha possui uma saída diária de cada capital, o maior número de usuários são moradores e trabalhadores dos municípios atendidos pela ferrovia. Já nos meses de alta temporada - dezembro, janeiro, fevereiro e julho - meses atrelados ao período de férias) o trem recebe um alto número de turistas que se aventuram em uma viagem longa que tem seu tempo de duração variável de acordo com a demanda do transporte de carga, podendo chegar a 14 horas de viagem ${ }^{3}$.

Como no caso de São João Del Rei, a Vale também mantém o Museu Vale na antiga estação ferroviária Pedro Nolasco na região portuária de Vila Velha (ES), construída em 1927 e restaurada entre 1996 e 1997. Além do Edifício Sede (Figura 5) que abriga o acervo permanente que contam a história da Estrada de Ferro Vitória a Minas, as salas de Construção, da Manutenção e das Estações são espaços expositivos que apresentam a história da ferrovia. Paralelamente são realizadas exposições temporárias de arte contemporânea de artistas nacionais e internacionais na Sala de Exposições Temporárias, localizada no Edifício Sede e no Galpão de Exposições - antigo armazém de cargas adaptado para exposições de grande porte.

Porém, ressalta-se que as ações são pontuais, como é observado no edifício pertencente a antiga Estrada de Ferro Leopoldina imediatamente atrás do Café do Museu e ao lado do edifício restaurado da estação Pedro Nolasco (Figura 5). 
Figura 5: Museu da Vale (Estação Pedro Nolasco) / Edifício Estrada de Ferro Leopoldina

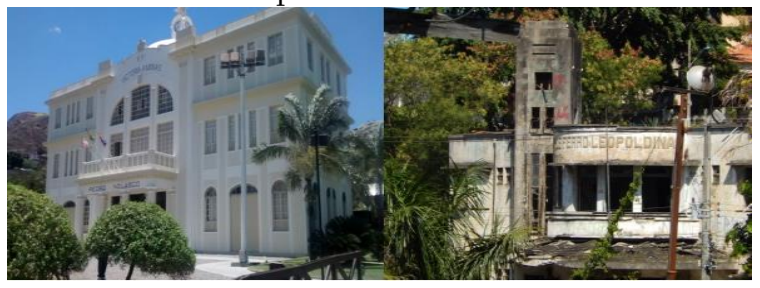

Fotos: Fernanda F. D'Agostini, 2012

No entanto, observa-se que este rico acervo se restringe aos turistas e moradores das cidades de Vitória e região metropolitana que se deslocam, em sua maioria, de carro próprio até o Museu, que não possui nenhuma ligação direta com a linha férrea ativa. Desta forma, o valor cultural agregado não atinge a maioria dos usuários do trem de passageiros, pois seu embarque e desembarque acontecem na Nova Estação Pedro Nolasco em Cariacica, cidade da região metropolitana, enquanto o Museu localiza-se na cidade de Vila Velha.

O Museu Vale conta ainda com um restaurante denominado Café do Museu que oferece um cardápio sofisticado assinado por uma Chef de cozinha. Em um ambiente agradável, além de nostálgico - adaptado em um vagão de passageiros, conforme demonstrado na figura abaixo, o preço é relativamente alto se comparado aos padrões da região e o serviço lento, com um tempo de espera de aproximadamente uma hora (conforme vivenciado por Fernanda D’Agostini em visita ao Museu em janeiro de 2015). Essa elitização do espaço segmenta o público visitante, assim como não permite maior permanência de todos no espaço.

No estado de Minas Gerais, integrando o plano de turismo associado às ferrovias locais, são oferecidos dois outros roteiros de passeios a bordo dos trens turísticos, que visam à valorização do patrimônio natural e cultura local. É o caso do Trem das Águas e o Trem da Serra da Mantiqueira. O Trem das Águas inclui em seu roteiro de aproximadamente 40 minutos de viagem entre a Estação Central de São Lourenço até a Estação de Soledade de Minas, um percurso de aproximadamente $10 \mathrm{~km}$; nele o turista pode usufruir das paisagens naturais das margens do Rio Verde (ABPF, 2014).

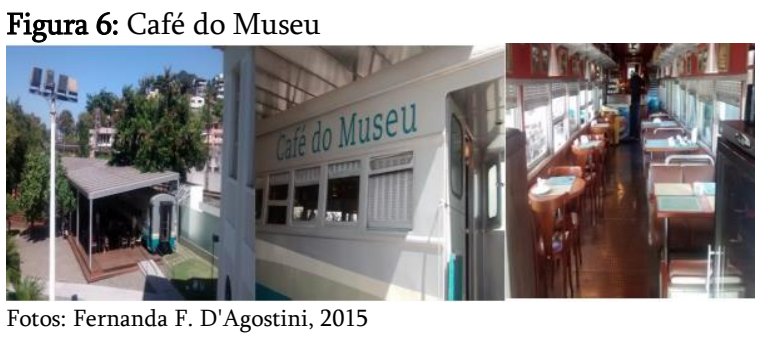

No estado de Minas Gerais, integrando o plano de turismo associado às ferrovias locais, são oferecidos dois outros roteiros de passeios a bordo dos trens turísticos, que visam à valorização do patrimônio natural e cultura local. É o caso do Trem das Águas e o Trem da Serra da Mantiqueira. O Trem das Águas inclui em seu roteiro de aproximadamente 40 minutos de viagem entre a Estação Central de São Lourenço até a Estação de Soledade de Minas, um percurso de aproximadamente $10 \mathrm{~km}$; nele o turista pode usufruir das paisagens naturais das margens do Rio Verde (ABPF, 2014).

Como diferencial do roteiro, a viagem é ambientada pela participação de violeiros que tocam músicas da cultura local e um carro de Classe Especial, em que os bancos são estofados, e o passageiro pode degustar de opções de vinho, cachaças, licores, além de queijos e doces da região. Na Estação de São Lourenço é possível fazer compras na feira de artesanato e nas lojas de bebidas e frios, contando ainda com a opção de um café onde é possível experimentar as guloseimas da região (ABPF, 2014).

Por fim, o Trem Turístico da Serra da Mantiqueira, tem partida na cidade de Passa-Quatro chegando à Estação Coronel Fulgêncio, no alto da Serra da Mantiqueira. Neste percurso, de aproximadamente $18 \mathrm{~km}$ - ida e volta - o turista conta com duas paradas, sendo a primeira em Manacá, onde a feira de artesanatos e culinária local são os principais atrativos, e a segunda, na Estação Cel. Fulgêncio. Nesta o turista depara-se com a exposição fotográfica das minisséries filmadas no local, como por exemplo, Mad Maria e JK, além da exposição de fotos de máquinas e carros recuperados pela $\mathrm{ABPF}$ e fotos da Revolução Constitucionalista de 1932 (ABPF, 2014). Tais paradas são um estímulo à permanência do turista nas diversas cidades por onde se dá o roteiro, complementado pela oferta de hospedagem, contribuindo para o desenvolvimento de atividades econômicas várias e complementares. 
Este roteiro, além da exploração das paisagens naturais e da produção local de artesanato e itens da culinária, diferencia-se pelo oferecimento de visitação a um dos túneis da ferrovia e pela manobra realizada pela locomotiva ao chegar na estação Cel. Fulgêncio que é feita com os passageiros a bordo. Nota-se a apropriação clara dos fatos relevantes ocorridos na região para a promoção do roteiro, alimentando a economia local através da venda de souvenires, comidas, entre outros.

\subsection{Roteiro Ferroviário Turístico em São Paulo: Luz - Paranapiacaba}

A viagem do trem turístico Estação Luz (São Paulo) - Paranapiacaba se caracteriza pela implementação de uma política contrária, onde não se verifica a integração prevista entre os produtos turísticos existentes e uma possível regionalização. Os municípios cortados pela ferrovia neste trecho não possuem planos de desenvolvimento integrado ao turismo e apresentam suas estações e equipamentos ferroviários sucateados.

Na implantação do turismo na Vila Ferroviária de Paranapiacaba observa-se que a ferrovia não é integrada aos planos estratégicos e de ação do turismo como elemento desenvolvimento local e regional, essa observação pode ser comprovada pela própria revitalização do Largo dos Padeiros, com a construção a qual "dá as costas” à ferrovia (Figura 7) e se aparta do entorno - da arquitetura local e paisagem.

Figura 7: Largo dos Padeiros - Vila de Paranapiacaba

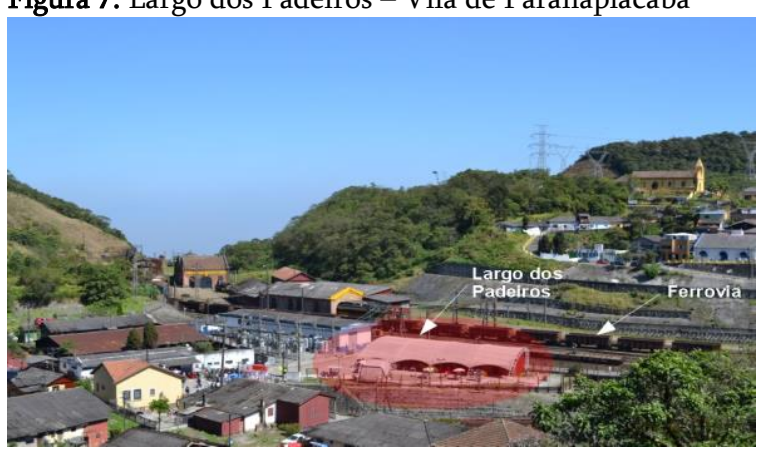

Fotos: Fernanda F. D'Agostini, 2015

O Largo dos Padeiros (Figura 7) é a praça de entrada da Parte Baixa por meio da passarela metálica que interliga as duas partes: Alta e Baixa. É tradicionalmente conhecida pela concentração de serviços - alimentação, receptivo e comércio de produtos turísticos e souvenires. Revitalizado em meados de 2007, o Largo dos Padeiros resgatou sua antiga importância, local de antigo galpão de consumo que atendia à antiga estação Alto da Serra e armazenava pães; o galpão foi demolido entre as décadas de 1940 e 1950. Atualmente é composto por sete barracas de alimentação com base em alvenaria e parte superior em madeira protegidas por uma cobertura em estrutura metálica circular translúcida, além de sanitários com fraldário e banheiro para pessoas com necessidades especiais.

Como nos dois outros casos apresentados anteriormente, neste roteiro turístico de Paranapiacaba também há a inserção do Museu Tecnológico Ferroviário, que aproveitou o sítio em que se localizavam o antigo pátio de manobras, as máquinas fixas, oficinas, carros, vagões, locomotivas e objetos de uso ferroviário dos dois sistemas funiculares que operaram no trajeto entre o Alto da Serra e a Raiz da Serra (trecho da Estrada de Ferro São Paulo Railway) como forma de resgate do patrimônio ferroviário, no entanto vale ressaltar que este museu se encontra dentro do perímetro de concessão da MRS, desta forma por muitas vezes sofrendo alterações esporádicas no horário de funcionamento conforme necessidades específicas da empresa em relação a manobras de trens e cargas e manutenção da linha.

Neste processo, a concepção de uma nova paisagem não respeitou as preexistências buscando novos equilíbrios ambientais, a recriação da memória viva e a reinvenção do sistema produtivo, evitando sua “museificação".

No caso da Vila Ferroviária de Paranapiacaba a implementação do trem turístico não possui uma preocupação clara com a valorização dos atrativos turísticos (paisagens naturais, culinária, artesanato e produtos locais) integrados à região e um plano estratégico para desenvolvimento local e regional, além da falta de integração intermunicipal que ocasiona a falência do sistema e a degradação do patrimônio.

\section{Considerações Finais}

Nos dias atuais, uma articulação entre poder público e a iniciativa privada se tronou um meio para a garantia de funcionamento dessas linhas turísticas. As concessões privadas gerenciam as ferrovias e os 
trechos em que se implementam roteiros turísticos, e por sua própria condição de capital privado dificultam uma eventual integração de fato com políticas públicas de desenvolvimento regional. A premência de um planejamento integrado de desenvolvimento se impõe como fundamental para a obtenção dos resultados de regionalização esperados. Porém, ressalta-se que o conflito de interesses é notório quanto a operação das linhas férreas, verificando-se lacunas nos contratos de concessão relativas por exemplo, à preservação dos bens patrimoniais, assim como ainda é possível verificar o privilégio do transporte de cargas frente ao de passageiros como no caso das viagens realizadas entre Curitiba - Morretes e Belo Horizonte - Vitória.

Em todos os casos estudados, a prioridade do transporte de carga é evidenciada, devido ao interesse direto das concessionárias que visam ao melhor desempenho dos serviços prestados; acarretando o privilégio aos interesses particulares. Esse privilégio representa um conflito inerente à gestão das concessionárias dos trens de turismo. Esta dificuldade se agudiza e revela, por muitas vezes, pelas interrupções dos roteiros turísticos e pelo privilégio concedido à passagem de um comboio de carga.

Zancheti (2000) pondera que a adoção de um sistema de gestão embasado na preservação ambiental e patrimonial transformou a conservação urbana em uma estratégia de agregação de valor à economia urbana e, tornou-se um instrumento de atração de investimentos privados, muitas vezes suprarregionais ou internacionais, atendendo a lógicas de produção do espaço globais, para além dos municípios e de suas articulações regionais.

Observa-se que em todos os roteiros de trem turístico acima descritos o turismo apropria-se da representação cultural local como forma de comercialização do espaço urbano. A questão principal desta discussão, no entanto, é a evidência da importância de planos ou projetos de implementação do turismo regional, em todos os exemplos descritos anteriormente há a intenção da inter-relação socioeconômica dos municípios para a criação de uma rede fortificada e autossustentável.
Uma das funções das ferrovias turísticas pode ser a efetiva integração dos municípios, valorizando os seus respectivos atrativos turísticos; assim, a ferrovia articula os municípios, proporcionando novos usos ao patrimônio cultural.

Jan Gehl (2013) afirma que para que as relações entre a vizinhança e as diversas formas de atividades comunitárias se desenvolvam além do nível superficial, é preciso que tenham um significativo denominador comum: interesses ou problemas comuns, ou eixo transformador em comum.

As ferrovias turísticas diferenciam-se pela gama de serviços e forma de comercialização agregados, como por exemplo, visitas monitoradas com distribuição de material promocional e distribuição de folhetos, além da venda de souvenires. Desta forma, dependem de um plano de marketing e canais de comercialização diferenciados que lhes garanta uma inserção no mercado do turismo - produtos turísticos, tais como: atrativos naturais, patrimoniais, entre outros.

Porém, sendo a atividade turística produto da sociedade capitalista industrial desenvolvido sob motivações diversas, incluindo o consumo de bens culturais (Rodrigues, 2012), o turismo cultural associado as ferrovias torna-se questionável quando interpretado como uma forma de atividade turística que se apropria de algo que possa ser caracterizado como bem cultural.

$\mathrm{Na}$ observação dos roteiros turísticos associados às ferrovias evidenciou-se a falta de interação do turista com os locais visitados e de passagem, não permitindo que as pessoas vivenciem por completo as experiências quanto as paisagens, ambientes e etc, a partir do momento que em vários pontos de interesse e trajetos não é possível descer do trem e em muitos casos a apreciação das paisagens naturais e do próprio patrimônio ferroviário (edificado) é feita através das janelas e vidros fechados que impedem de sentir os cheiros, temperaturas, além de modificar as cores e a luz, por exemplo.

O valor agregado aos elementos arquitetônicos e urbanísticos enquanto suporte da memória social e à sua representatividade regional é reflexo do intercâmbio econômico e social engendrado pela ferrovia e suas conexões neste território no final do 
século XIX e início do século XX, contrapondo-se ao abandono e deterioração do patrimônio, além da estagnação do desenvolvimento local. Grande parte desta problemática refere-se a pouca efetividade das políticas públicas orientadas ao reconhecimento e preservação do patrimônio cultural edificado em nível local (RIGON et al., 2014).

Verifica-se que o conjunto de ações políticas e econômicas voltadas para o turismo gera algumas implicações espaciais, em alguns casos o fator cultural está no centro dos projetos identificando o fenômeno decorrente da globalização: o empresariamento urbano e o turismo.

O sistema turístico, no entanto, pode segregar, criar enclaves e guetos, gerar não lugares em vez de integrar, estimular e enriquecer a realidade existente, além contribuir para a expulsão dos habitantes e desaparecimento do comércio cotidiano, para tanto se torna necessário a análise dos indicadores de medição da capacidade de carga de cada cidade ou ponto turístico para a implantação de políticas públicas de contenção e regulamentação da atividade turística em prol do desenvolvimento urbano e regional.

$\mathrm{Na}$ história do desenvolvimento das cidades por séculos as ferrovias foram consideradas elementos estratégicos de conexão e crescimento, em 1852, por exemplo, Haussmann em seu programa para Paris evidenciou a importância da interligação das estações ferroviárias aos centros comerciais e de lazer por vias diretas de acesso como meio de facilitar o fluxo da cidade (AYMONINO, ??).

Atualmente o Brasil implanta projetos turísticos para preservação e manutenção do patrimônio ferroviários proporcionando um pequeno desenvolvimento local como descrito neste artigo, porém a desconexão entre as ferrovias turísticas com a cidade e outros pontos de interesse e entre elas próprias dificulta o desenvolvimento de um plano integrado.

O desenvolvimento local em áreas cujo patrimônio cultural é parte da equação, em que a ferrovia é fundamental ao entendimento do patrimônio para o desenvolvimento da região com a finalidade turística, é uma problemática complexa, tornandose necessário um planejamento integrado capaz de articular os interesses municipal e regional. Assim, o ponto de convergência desse planejamento integrado é a ferrovia, interesse comum a vários municípios e ausente na abordagem dos planos turísticos implantados nas ferrovias turísticas, que relegam à ferrovia um papel menor, gerador de um "turismo do isolamento".

Desta forma, entre a planificação nacional e a municipal (planos estaduais e regionais) é necessário um equilíbrio entre os setores econômico-social e físico territorial, em um esforço comum ao desenvolvimento igualitário das cidades.

\section{Referências}

ABPF - Associação Brasileira de Preservação Ferroviária. Trem da Serra da Mantiqueira. Disponível em: <http://abpfsuldeminas.com/ tremda-serra-damantiqueira/>. Acesso em: 26 fev. 2013

Trem das Águas. Disponível em: <http://abpfsuldeminas.com/trem-dasaguas/>.

Acesso em: 26 fev. 2013.

ALLIS, Thiago. Turismo, patrimônio cultural e transporte ferroviário: um estudo sobreferrovias turísticas no Brasil e na Argentina. Dissertação. (Mestrado em Integraçãoda América Latina). Programa de Pós-graduação em Integração da América Latina - USP, São Paulo, 2006.

AYMONINO, Carlo. El Estudio de los Fenómenos Urbanos. In: CANIGGIA; Gianfranco, AYMONINO, Carlo; SCOLARY, Massimo. Análisis Urbano. Sevilla: Alfonso del Poso ed.

CYRINO, Fábio. Café, ferro e argila: a história da implantação da The San Paulo (Brazilian) Railway Company Ltd através da análise de sua arquitetura. São Paulo: Landmark, 2004.

FCA - Ferrovia Centro - Atlântica. Histórico. Disponível em: <http://www.fcasa. com.br/sobre-afca/historia/>. Acesso em: 17 out. 2014.

GEHL, Jan. La humanización del espaço urbano. 2a Reimpressão. Editorial Reverté: Barcelona, 2013.

JENKINS, Carson L.; LICKORISH, Leonard J. Introdução ao Turismo. Rio de Janeiro: Campus, 2000. 
KÜHL, Beatriz Mugayar. Preservação do Patrimônio Arquitetônico da Industrialização - Problemas teóricos de Restauro. São Paulo: Ateliê Editorial, 2009.

MAZZOCO, Maria Inês Dias; SANTOS, Cecília Rodrigues Dos. De Santos a Jundiaí: nos trilhos do café com a São Paulo Railway. São Paulo: Magma Editora Cultural, 2005.

MONTANER, Josep Maria; MUXI, Zaida. Arquitetura e Política: ensaios para mundos alternativos. São Paulo: Gustavo Gili, 2014.

RIGON, Matheus José, FUJITA, Camila, VILLELA, Ana Laura Viana. A ferrovia, as cidades e o território: Paisagem ferroviária e patrimônio cultural edificado no trecho Erechim-Piratuba da antiga estrada de ferro São Paulo-Rio Grande. Vitruvius, set. 2014. Disponível em: $<$ http://www.vitruvius.es/revistas/read/minhacidad e/14.170/5273>. Acesso em: 8 set. 2014.

RODRIGUES, Marly. Preservar e Consumir: o patrimônio histórico e o turismo. In: FUNARI, Pedro Paulo. PINSKY, Jaime (orgs.). Turismo e Patrimônio Cultural. São Paulo: Contexto, 2012.

RFFSA - Rede Ferroviária Federal Sociedade Anônima. Histórico. Disponível em: <http://www.rffsa.gov.br/principal/historico.htm>. Acesso em: 20 out. 2014.

SOMEKH, Nadia (org). Preservando o Patrimônio Histórico: um manual para gestores municipais. São Paulo: DPH, 2014.

TONON, Luciana Maria Pinheiro. A Territorialização e o Marketing de um Produto Turístico Regional: O Passeio de Trem Curitiba/Litoral. Dissertação (Mestrado em Geografia) - Setor de Ciências da Terra, Universidade Federal do Paraná, Curitiba, 2014. Disponível em: <http://dspace.c3sl.ufpr.br/ dspace/bitstream/handle/1884/35878/R\%20-20 D\%20-\%20LUCIANA\%20MARIA\%20PINHEIRO $\% 20$ TONON.pdf?sequence $=1>$. Acesso em: 20 out. 2014.

VALE S.A. Trem de Passageiros da EFVM. Disponível em: <http://www.vale.com/brasil/PT/ business/logistics/railways/Passenger-
TrainVitoriaMinas/Paginas/default.aspx $>$. Acesso em: 20 out. 2014

WEARING, Stephen. NEIL, John. Ecoturismo: impactos, potencialidades e possibilidades. São Paulo: Ed. Manole, 2001.

ZANCHETI, Silvio Mendes. Conservação Integrada e Novas Estratégias de Gestão. In: 4o Encontro do SIRCHAL, Salvador, 2000. Disponível em: <http://www2.archi.fr/SIRCHAL/ seminair/sirchal4/ZanchetiVPT.htm>. Acesso em: 30 mai. 2014. 